\title{
An Empirical Survey of the Present English Learning State of Male Students in Rural Areas
}

\author{
Lei Yang ${ }^{1, a}$ \\ ${ }^{1}$ Wuhan Institute of Technology, NO. 1 Liu Fang Avenue Jiangxia District Wuhan City Hubei province \\ aemail,
}

Keyword: Countryside; Second-Year Male Students; English Study; 3D Teaching Method

\begin{abstract}
According to some theories on Second Language Acquisition and English Teaching Methodology, this thesis studies on the present English learning state of boys in rural middle school. First, taking the advantage of being an internship teacher in Mont, Lu Bai Lu Foreign Language School in Jiujiang, Jiangxi Province, the author conducts some surveys on the contemporary English learning state of the second-year boys in this rural middle school by exam and questionnaire. And its shows that boys do worse than girls in almost all English learning items especially in grammar and writing. Second, the author analyses the reasons from students themselves, teachers and the social environment by questionnaire and interviewing the teachers. The emphasis is placed on how to improve the teaching methods. Based on the results and Kreshen's inputs hypothesis, the author puts forward "3D teaching method”. "3D” means three dimensions, including density, breadth, and depth. The statistics of the experiment prove that the "3D teaching method" contributes a lot to the progress of boy's English learning in rural areas.
\end{abstract}

\section{Introduction}

The $21^{\text {st }}$ century is an era of science and technology which develops very rapidly. With China's economic, scientific and technological development, especially its entry into the WTO and successful holding of the 2008 Beijing Olympic Games, the status of English as an international language has been highlighted since 1980s in China.

However, after 20 years' English education, our students' English proficiency is still far from what we have expected, especially in rural areas. And it is worthwhile to point out that boys achieve much less than girls in English in such areas. Actually, many researches have been done in the last 20 years, such as:

On The Effects of Gender Difference in English Study. Since 1960s, when movement of liberating women sprouting within America and sociolinguistics coming into born, gender language has been paid great attention to.

In 2003, Mikel found in his research that girls could master complicated language skills one year earlier than boys. Compared with peer boys, pre-school girls had a higher speed in reading, and larger vocabulary and spoke more grammatically. What's more, researches both in China and Hong Kong show that a greater number of girls attend foreign language classes, and they perform better than boys, particularly in reading and writing. Girls own more interests in foreign language study

From the study on gender difference in China in 2008, it is found that female students are more interested in Chinese and foreign languages than the male. At the elementary school and junior high school stage, traditionally, girls are more likely to attain achievements because they have more desire to get approval and praises and they are more obedient. However, the boys at this stage are likely to form bad reading habits, have poor grades, and might also have behavior problems even drop-out.

On the State of English Teaching in Rural Areas. Zheng Men, as well as Ye Zaitian, Fu Zhanshen, Xu Jianfeng(2000), Wang Min(2003) and Chen Yingying made a study and description on the state of English teaching in junior high school. The findings are classified into the following two aspects: one is the faculty aspect, including the low academic level, less use of classroom English and outdated teaching ideas, etc. The other is the English learning environment, including the bad influence of social environment and family environment in rural areas. 
Furthermore, Hu Jin (2007) analyzed English teaching features of rural junior high schools as follows: Firstly, students study English in a bilingual environment, therefore, unavoidably mother tongue has great interference on their English study. Secondly, the teacher is the only source to impart English knowledge into students. Shortage of teaching media such as books, newspapers, sound recording, video recording, charts, CD, microcomputer etc. causes English study to be lack of information resources. Thirdly, textbook is the core of teaching. Fourthly, classroom teaching is the only form to learn English.

Although these studies are of significance, they are limited in macro level. In order to thoroughly understand the current state of boys' English learning in rural areas, based on the theory of second language acquisition, the author carried out a survey on the second-year students in Mont.Lu Bailu Foreign Language School, which aims to dig out the weak points of students' English learning and try to supply solution to each of them, thus, improving our teaching and students' learning.

\section{Research Design and Implementation}

Participants. The participants in the survey are 100 second-year students(50\%-50\%, boys-girls) from the countryside middle school Mont.Lu Bailu Foreign Language School, where the author of this thesis worked as an internship English teacher for 2 months. They are sampled from class 1 (41boys,26 girls), and class3(29boys, 35girls), who share the same English teacher, Miss Huang. 25boys and 25 girls are sampled from class 1 and the rest from class3. Their ages range from twelve to fourteen and they are all from the countryside.

Instruments. The instruments used in this research are exam paper, questionnaire and Access 2003.

Exam paper and questionnaire are the most common methods for data collection in L2 survey because of their less time consumption and less expense. And in this study the author adopts them as major data collection instruments.

In order to give accurate judgments with the collected data, Access2003 is adopted for statistic analysis as well.

Procedure. Sampling: the participants are sampled from class land class 3, grade 2 in Mont.Lu Bailu Foreign Language School. There are altogether 100 participants investigated, 50 in each class, including half boys and half girls. The subjects are chosen randomly from their classes.

Exam: exam paper consists of the following five items: listening, vocabulary, grammar, reading and writing, which Is designed to discover which part of English is the weakness of the second-year rural boys' English learning.

Questionnaire: according to educational psychology, students' study is mainly affected by three factors, namely, students themselves, teachers and environment. Among them, the inner elements that influence students' study including study motivation, sense of acquisition, and study strategies while teachers affect students mainly by teaching attitude and teaching methods. Based on educational psychology, therefore, the questionnaire is composed of 25 multiple-choice questions. Question 1-10 are designed from the students' perspective, including study motivation, sense of acquisition, and study strategies. Question 11-20 are about teachers, such as teaching attitude, teaching method, and the last 5 questions are about social environment. Designed in Chinese for easy intelligibility and accessibility, the questions intend to discover the reasons why boys are poorer in English compared with girls.

In the investigation, one hundred exam papers and copies of the questionnaire are collected and all of them are valid and significant to the research.

Data analysis: all the data from exam and questionnaire are analyzed through Access 2003. After tedious and hard calculating work, relevant statistics with their percentages are collected, which will be illustrated in the form of table in the following.

Besides the data from questionnaire, the information collected from observations and interviews is important as well. 


\section{Results and Analysis of Reasons}

Weak Points. It is known to all that boys have disadvantages over girls in English learning. However, where those disadvantages lie still remains unclear. So the first thing the author have done in this survey is on these. The author first holds a test among students. And after analyzing the results of the exam, the present weak points of boys in English appear clearly in some parts.

The second-year students' English learning is divided into five parts in the tables for convenience. Through the result, girls' English is much better than that of boys in both classes. Grammar and writing are the two biggest headaches in boys' English study. Thus, how to help boys improve their writing, master grammar effectively and put them into flexible use are worth our research.

Reasons. Causes of the existing phenomena are multiple. In order to find out the causes, the author makes a questionnaire, designed from three perspectives of students, teachers and social environment as a whole (See 2.3) and will introduce respectively as follows.

Resulting from students. Lack of study motivation and vagueness of study targets. Psychological barrier is a serve problem in rural boys' English study Psychological factors are non-intellectual factors, including studying motivation, attitude, interest, will and so on.

When asked "where do the motivation and interest of your English study come from", 54 percent of girls show that they love the subject very much while 66 percent of boys study English just for exams. When asked "why do you study English hard", 40 percent of girls answer they like it, while 50 percent of boys do it to meet the requirements from teachers or parents. From the reaction of girls and boys toward the two questions above, it can be seen that most girls have firm inner motivation and interest in English learning, while most boys study English due to external driver such as need of exams, entering a key school, finding a good job and requirement of teachers and parents.

Therefore, lack of inner study motivation and vagueness of study targets is a big obstacle preventing boys from achieving much in English study.

Lack of study interest and sense of achievement. The statistics of questionnaire show that 60 to 70 percent of students usually study English about half an hour, that is to say, the time boys and girls spent on English are enough, but their achievements are rather different. When asked further "can you learn English well", 46 percent of girls say definitely yes while half boys consider it hard to say, more important is that 38 percent of boys think they can not. For this part, it tells us that boys mostly have a sense of inferiority and a low mood, so most boys are lack of activeness in their English study, and their interest in English falls to the bottom.

Therefore, lack of studying interest and sense of achievement is a lion in the way of boys'English study.

Lack of proper and effective study strategies. The statistics of questionnaire show that more than 70 percent girls always or often prepare and review a lesson while nearly half boys do it only when being required. What is worse, there are 20 percent of boys never pre-read or review. To some extent, bad studying habits such as seldom previewing the lesson, or reviewing what they have learned in class make them completely forget what they have learnt after the teaching hours. Gradually, a kind of sloth troubles them.

Most often, the so-called "bad boys" lose their heart in learning English and do not know where to start their English study or how to learn, so they can not form a set of methods which are appropriate to themselves.

Therefore, lack of proper and effective study strategies also lead to boys' less achievement. In addition, there are other causes contributing to the phenomenon. For example, girls are careful to help themselves master numerous grammar and complex morphological conversion etc, while boys are relatively careless and easy to ignore some details. That is why boys are poorer in grammar and writing, to some extent.

Resulting from society. English learning is becoming more and more popular in China, especially after China's successful bidding and holding of the 2008 Olympics. The whole society is putting ever increasing importance to the English study. Therefore, heavy pressure on students at schools is from different sources like our society, parents, teachers, and other institutions, which make students over-loaded and exhausted. Students are struggling to live up to the great expectations of the various 
sources, otherwise they will 'fail' in their life and in their future career. Therefore, they can never have any intervals and breaks for relaxation.

Another cause from society is more objective. Since China is a country with large population, the classroom is often overpopulated. But the nature of the classroom capabilities such as listening and speaking requires a huge amount of repeated exercises, and every student needs sufficient chances for practice. In the investigation, we have found that most classes have an overloaded capacity of 60 to 70 students. With such a large classroom population, teachers find it hard to conduct spoken English activities, thus eliminating the chances of students' oral English practice. Consequently, the students' oral English is hard to be elevated. Besides, lacking of hardware facilities and capable teachers are also obstacles in the way of rural education.

\section{Measures for Improving the Boys! English Learning}

As is mentioned in the last chapter, three factors, namely, students themselves, teachers and society exert great influence on the boys' English study. The boys can improve their English by adopting certain study strategies and by forming good habits. What's more, school, family and the society can make efforts to create appropriate and beneficial study environment.

However, boys at this age are not usually laden with self-disciplined capability, and social environment can not be improved overnight. So it is a key step to adopt efficient teaching methods. How to involve every student into classroom teaching activities and make it actively and efficiently are critical to this problem. Correspondingly, the author puts forward a 3D teaching method and applies it into classroom teaching when she is an internship teacher in Mont. Lu Bai Lu Foreign Language School. This method is proved to be very efficient according to her teaching experiment.

Teaching Method. Nowadays, ordinary junior classroom usually consists of more than 60 students, which is defined as a large class according to David Hayes. ( David Hayes, 2006) The old teaching method mentioned above is one-way transmissive. So how to give every student a chance to communicate, perform in the large classroom, embody a new sense of language application successful and to reach the goal of learning to use language, are big problems for educators to carefully think about. The 3D teaching method can be adopted here to improve rural English large-class teaching.

Teaching Experiment on the Application of 3D Teaching Method. The primary intent of this thesis is to help rural boys enhance their English. However, the application of 3D teaching method into classroom teaching may bring changes not only in grammar and writing, but also in other items. The author, firstly, puts 3D method into application in class3. After 45 days' experiment, an exam is held to evaluate how much progress the boys have made. And through analysis of results of the exam, we can find that whether it plays an important role in improving boys' English.

\section{Conclusion}

Since China is a large agricultural country, education in rural areas is quite important in making it a powerful country in the world. The elementary and middle school education, which is the base of the whole education system, is especially critical. However, there are a lot of problems in rural education. And that boys are poor in English is one of them.

In order to get the first-hand data of the current state of the rural boys' English learning, the author carries out a survey among the second-year students in Mont. Lu Bai Lu Foreign Language School. 100 students in the school participate in this survey. By analyzing the participants' final exam results, the author finds: 1) boys' English is much poorer than the girls'; 2) grammar and writing are the two biggest headaches in boys' English study. Through the questionnaire and interviews, the author finds that many factors lead to the phenomenon and teachers' teaching method is one of the most important one.

Accordingly, 3D teaching method is put forward by the present author. By the application of 3D teaching method, it is found that both girls and boys improve greatly in English study and boys own great potential in English learning. Statistics show that boys have made greater progress in English. 
That is to say, through proper direction, boys in rural areas can learn English well, even better than girls.

Though the author has made great efforts in this survey, the contributions remain minor and less significant, to some extent. The concrete solution to the problems is mainly proposed from perspective of teachers. Further studies can be done from students themselves, social environment, effects of gender difference in physiological and psychological aspects and so on.

Even so, the author thinks the study has certain theoretical and practical significances to the boys' progress in English learning and the basic English teaching reform.

\section{References}

[1] Coles, M. J \& W. D. Robinson Teaching Thinking: A Survey of Programmes in Education. In Williams, M \& R. L. Burden, Psychological for Language Teachers [M] New York: Cambridge University Press, 1997:246

[2] Ellis E. The Study Of Second Language Acquisition [M] Oxford: Oxford University Press, 1994. 176-185.

[3] John Nisbet \& Janet Shucksmith. Learning Strategies. Routledge \& Keyun Paul Ltd, 1986:168.

[4] Krahen, S. D. Principles and Practices in Second Language Acquisition. Elmsdord, New York: Pergamon, 1982. 